\title{
Blistering skin disease in a man after injections of human placental extracts
}

\section{J-H Saurat, L Didierjean, Y Mérot, D Salomon}

\section{Department of}

Dermatology, Hôpital

Cantonal Universitaire,

1211 Geneva 4, Switzerland

$\mathrm{J}-\mathrm{H}$ Saurat, MD, professor and chairman

L Didierjean, PHD, biologist

Y Mérot, MD, registrar

D Salomon, MD, registrar
Several tissue specific autoimmune disorders can be induced experimentally in animals by immunisation with tissue antigens and Freund's adjuvant. There are few examples in humans of organ specific autoimmune disease induced by injecting related tissue antigens. The hazards of injecting extracts of human tissues have not been fully considered, although this practice is becoming popular in the quest for maintaining youth. We report on a man who developed antibodies against human skin antigens and lesions similar to the autoimmune skin disease bullous pemphigoid after injections of extracts of human placental tissue.

\section{Case report}

A man of 79 presented with a two week history of pruritic erythematous vesicular eruption on the chest, arms, and back. Bullous pemphigoid was diagnosed from the results of skin histopathology; direct immunofluorescence of erythematous perilesional skin, which showed linear deposits of IgG, IgM, and C3 in the basement membrane zone; and indirect complement immunofluorescence, which showed circulating antibodies against the basement membrane at a titre of 8 . Prednisone $(0.5 \mathrm{mg} / \mathrm{kg} /$ day) and chlorambucil $(6 \mathrm{mg} /$ day) were given, and the skin condition started to heal without scarring.

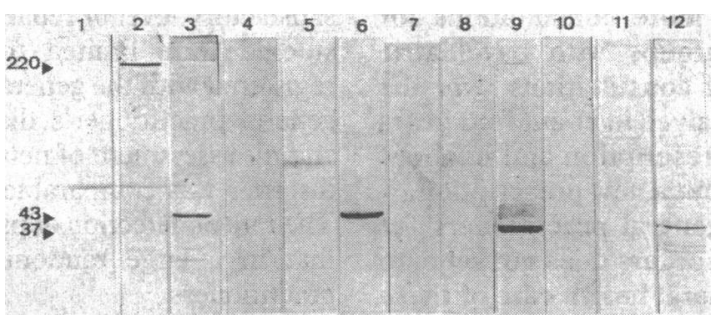

Protein blot analysis of normal human skin (lanes 1-3 and 7-9) and human placental extracts (lanes 4-6 and 10-12) reacted with normal human serum (lanes $1,4,7$ and 10) bullous pemphigoid serum (lanes 2 5,8 , and 11), and patient's.IgG (lanes 3 and 6) and IgM (lanes 9 and 12); lanes 1,-6 were incubated with anti-IgG serum and lanes 7-12 with anti-IgM serum. Patient's IgG reacted with band at 43 kilodaltons in both skin (lane 3) and placental extracts (lane 6) and his IgM reacted with band at 37 kilodaltons in both (lanes 9 and 12); bullous pemphigoid serum (lane 2) reacted as expected with a band at 220 kilodaltons

Later several firm subcutaneous nodules were observed in sites injected with placental extracts by his wife at his request. These extracts were prepared from "total human full term placentas" with no "foreign chemical or enzymatic factors" added, each vial $(2 \mathrm{ml})$ containing "the equivalent of $0.2 \mathrm{~g}$ of the fresh organ." The extracts were recommended for "all the cases when the body necessitates biological stimulation." $\mathrm{He}$ had received two injections each month for a year. Then he received one injection $(2 \mathrm{ml})$ for seven consecutive days, followed by one injection every third day; the pruritus and the erythematous rash appeared after the fifth daily injection and the bullae erupted after the third day of spaced injections. He received extracts equivalent to $2 \mathrm{~g}$ fresh human placenta during the 16 days before admission. As human amnion has similar antigens to skin $^{12}$ we hypothesised that he might have a distinct disease caused by the extract and performed the following studies to investigate this.

Immunoelectron microscopy of his skin showed linear deposits of $\operatorname{IgG}$ and patchy focal deposits of $\operatorname{IgM}$ within the lamina lucida of the basement membrane. Patchy granular deposits of IgM were also seen at the top of dermal papillae beneath the lamina densa. Indirect immunoelectron microscopy of normal skin incubated with his serum showed linear deposits of IgG within the lamina lucida and patchy granular deposits of IgM at the top of dermal papillae. A protein blot analysis of normal human skin and human placental extracts showed that in both his IgG reacted with a band at 43 kilodaltons and his IgM with one at 37 kilodaltons (figure).

\section{Comment}

Our patient developed a blistering skin disease similar to bullous pemphigoid but without detectable antibodies to the bullous pemphigoid antigen (220-240 kilodaltons).$^{34}$ Instead his serum reacted with antigens in both the placental extracts and the epidermal basement membrane. Neither the serum samples of five patients with bullous pemphigoid nor the normal control serum samples reacted with such antigens. These antibodies were therefore probably induced by the injections of the placental extracts. As they reacted with antigens situated at the dermoepidermal junction the antibodies probably had a role in the cutaneous lesions similar to that of antibodies in spontaneous bullous pemphigoid. ${ }^{34}$

Because of the peculiar nature of this treatment it is difficult to set up a prospective or even a retrospective study of patients receiving placental extracts to evaluate the incidence of antibodies to cutaneoplacental antigens, even in those without skin symptoms. We think, however, that our patient might be exceptional because he received two injections a month for about a year and then a booster series of daily injections. He developed subcutaneous nodules, implying a strong inflammatory response around the injected antigens. Such a reaction might be similar to the effect of Freund's adjuvant in experimental animals. We assume that he developed clinical disease because immunisation was more effective than in other patients receiving such extracts.

We thank Drs G Lazarus and J McGuire for their help in preparing this manuscript, Messrs P Carraux and C Fournier for technical help, and Ms S Deschamps for secretarial assistance.

1 Verrando P, Ortonne J-P, Pautrat G, Hsi B-L, Yeh C-J G. Identification of a 37 kilodalon protein at the epidermal basement $\mathrm{memb}$. Iden by an antiserum to kilodalton protein at the epidermal basement me

human amnion. F Invest Dermatol 1986;87:190-6.
Robinson HN, Anhalt GJ, Patel HP, Takarashi Y, Labib RS, Diaz LA. Pemphigus and pemphigoid antigens are expressed in human amnion epithelium. I Invest Dermatol 1984;83:234-7.

3 Norman K. Bullous pemphigoid. F Am Acad Dermatol 1987;16:907-24. 4 Katz SI. Blistering diseases. New Insights. N Engl f Med 1985;313:1657-8.

(Accepted 23 May 1988)

\section{ONE HUNDRED YEARS AGO}

In the pass-list of the Intermediate Examination for the M.B. degree of the University of London, which has just been published, we notice the names of no fewer than twelve students of the London School of Medicine for Women. Whatever may be thought of the general fitness of women for the practice of a profession so harassing to mind and body as that of medicine, it is satisfactory to find that so many of those who have resolved to embark on that career are preparing themselves for it with such thoroughness as is implied in the course of study necessary for obtaining a medical degree from so exclusive a body as the London University. (British Medical Fournal 1888;ii:325) 